\title{
Up and down and sideways: Collaboration, friction and ethnographic representations of orthodontics for children
}

Anette Wickström

The self-archived postprint version of this journal article is available at Linköping University Institutional Repository (DiVA):

http:// urn.kb.se/ resolve?urn=urn:nbn:se:liu:diva- 154810

N.B.: When citing this work, cite the original publication.

Wickström, A., (2019), Up and down and sideways: Collaboration, friction and ethnographic representations of orthodontics for children, Ethnography, , -17.

https:// doi.org/ 10.1177/ 1466138119829155

Original publication available at:

https:/ / doi.org/ 10.1177/ 1466138119829155

Copyright: SAGE Publications (UK and US)

http:// www.uk.sagepub.com/home.nav 


\title{
Up and down and sideways. Collaboration, friction and ethnographic representations of orthodontics for children
}

\begin{abstract}
In this article, I discuss collaboration and my experiences of involving orthodontists when representing orthodontic practice. Drawing on an ethnographic study with children and young people getting fixed appliances, the aim is to understand the politics of the practitioners' receptions of the research result. First, I explore the power balance involved in researching expertise in general. Studying up and down and sideways in a multidirectional collaboration, I demonstrate that direct focus on the practitioners' reactions to the ethnographic representations can reveal the political and social processes in institutions that deeply affect the lives of children. Secondly, the ethnographic examples show the specific changing conditions within the field of orthodontics that influenced how my analysis was received by the orthodontists. I argue that the result of collaboration, in the form of both agreement and friction, serves as knowledge about the burning questions of the institutional network under study.
\end{abstract}

\section{Keywords}

Collaboration, power dimensions, ethnographic representations, friction, orthodontics, children and young people, health and esthetics, politics of audience receptions, studying experts

\section{Introduction}

"The picture in your article does not concern orthodontics. It might be relevant for the US but not for state financed orthodontics in Sweden”, argued an orthodontist; and another one agreed firmly: "It is not appropriate to use this picture!” I was visiting one of the orthodontic clinics where I had done fieldwork over a couple of years and found that the orthodontists were upset with the article in which I discuss normalization processes in orthodontics (Wickström, 2016). The picture shows a billboard featuring a teenage girl hiding her teeth with her lips. The written message from the Swedish national dental health service reads: "Make a contract and secure your smile”. The reason why I included the picture in my article was to illustrate that state-financed dental services in Sweden involve marketing campaigns that present norms about how teeth and smiles should look. In my effort to describe the network of forces that children and young people are part of, the people who had let me study 
their practice perceived themselves as portrayed in an unfavorable way. How could I connect their work with the message in a billboard from another Swedish region? the orthodontists wondered. It did not represent their work. They did not recruit patients like that.

After having read what I wrote (cf. Brettell, 1993), the orthodontists found my representations of orthodontic practice problematic. I was bombarded with questions and it seemed as if they felt betrayed. The questions concerned the billboard, but also what qualitative methods may contribute and how the Swedish Research Council makes grants. The responses to my article were unexpected. As with Karen M. Staller's (2012) examples of epistemological tensions, I found myself in a disadvantaged position relative to the positivist standpoint that is at odds with qualitative methods and process-related questions. This was what I found during the meeting, but there was more at stake.

After distancing myself and recapitulating the meeting, I realized that the collaboration between me as a researcher and the orthodontists as specialists had involved fluctuating power positions. Collaboration and interaction with surrounding society have, in recent years, become incentives in research policies. Researchers’ successes in interacting and collaborating with surrounding society are being measured and constitute criteria for appropriation by higher education institutions (e.g. Wise et al., 2016). Mutual benefit and knowledge development are emphasized whereas friction, tensions and power aspects are seldom touched upon. My collaboration with orthodontists emanated from a shared interest in the research topic on normalization processes. The ethnographic field study had been initiated because of a call of distress from the orthodontists themselves. The director of the orthodontic clinics had stated in an interview in a local newspaper that the clinicians were under increasing pressure from parents and young people who wished to have treatment with braces even though they had no valid reasons for receiving state-financed treatment (Boström 2010). Against this background, the director showed great interest when I contacted her and she agreed to collaborate in the research project. During the meeting, however, the collaboration seemed to have broken down.

While considering the reactions to my article I found that I had put my finger on a troublesome aspect of orthodontics, namely the weight of esthetics in arguments for treatment not only among patients but in the practice of orthodontics as well. My analysis of how normalization operates in practice was based on the working of scientific classifications and visualizations of children's bites. I had also paid attention to how advertising as well as 
orthodontists' talk and gestures presented esthetic norms and ideals. The orthodontists, however, did neither seem to expect advertising in other regions being relevant for the study, nor that they themselves would be subjected to analysis.

In this article, I discuss my collaboration with the orthodontists. I investigate the dilemma involved in building a good relationship to the practitioners and sharing the results with them while at the same time retaining the ability to write critically (cf. Fangen, 2005). When the feedback succeeds, it may help to improve practice and keep the door open for further ethnographic investigations. When it does not succeed in one way or another, it is easy to yield to hopelessness and assertiveness or refer to different epistemologies as explanations (cf. Rosaldo, 1986), as I did initially. Renato Rosaldo (1986) refers to a third reaction in which the insights emerging from the research are emphasized. The insights are thought to overweigh the misunderstandings in that they can provide understanding of the differences between the way an ethnographer represents a practice and the way the practitioners see their work (Rosaldo, 1986). What I argue here is that the result of collaboration, not only in the form of agreement but also of friction, may serve as knowledge about the crucial point or the burning question of the phenomenon in question. Friction that arises in the form of conflicting views and contradictions may work as knowledge about what is at stake politically and socially in the field of study. The reactions to the feedback, whether interest or antagonism, are worth analyzing. I assert that direct focus on the practitioners' reactions to the ethnographic representations is useful when trying to understand the political and social processes in organizations that, as in this case, are responsible for safeguarding children's and young people's health. Thus this article will develop the discussion along two lines. First, I will discuss social science research on professional experts from a general point of view and the balance that arises in collaboration projects. Second, I will discuss the social and political changes going on within the field of orthodontics to demonstrate how these changes had an effect on how my analysis was received by the orthodontists.

\section{Power relationships in ethnographic field work}

In her thought-provoking and now classic article on "studying up”, Laura Nader (1972) urges anthropologists to study the institutions and organizations that shape people's attitudes and to some extent form the everyday aspects of people's lives. Her argument is that studying those who have been delegated the power to assume responsibility for medical care or legal and enforcement systems, for example, makes scientific work more relevant because it makes 
society more democratic. "Citizens need to know something about the major institutions, government or otherwise, that affect their life (Nader, 1972: 294)”, the systems which at times strongly influence the direction people's lives take (p. 300). Since her article was published, various aspects of ethnographic representations and of studying networks of power have been discussed. One of these aspects is that studying influential social institutions requires an awareness of the researchers’ own social positions. Gaztambide-Fernández and Howard (2012) draw on their experience from ethnographic studies of elite schools and question the vertical metaphor Nader used. A critical awareness of the privileged position held by researchers is needed if we are to address the role that privilege play in the research participants' lives, they argue. Researching elites requires a focus on the power dynamics between the researched and the researcher (Gaztambide-Fernández \& Howard, 2012). Being a researcher is a status position, and ethnographic writing involves the preferential right to interpretation. In research practice, status dynamics both shape and shift throughout the research process, and social and cultural barriers are constantly being negotiated.

To reduce the issue of power, scholars have turned to collaborative action research (e.g. Erickson, 2006; Hammond \& Spindler, 2001). The concept of 'study side by side’ refers to efforts to engage with the study objects as partners (Erickson, 2006: 239). In studying journalists, Boyer and Hannerz (2006) engaged in 'studying sideways' in the sense that they wished to explore parallels and similarities between their own work and journalists who work across distances, instead of instinctively being critical of journalism. Gusterson (1997) built spaces to converse with the research participants in public in order to avoid objectifying and exoticizing the weapons scientists he studied and at the same time incite new conversations of power. However, issues of power are not removed from the research relationships. Though arguing for studying side by side, Erickson (2006: 254) comments that the researcher risks coming too close to the practitioners and identifying with them and their view of the matter. Collaborative action research does not necessarily mean fewer dilemmas and considerations of how to give an account of a practice. What it implies rather is that all research has to be understood as a process of representation, whether it is a more traditional kind of research or collaborative action research. The accounts given of the participants "are still subjected to the mediating effects that all forms of social analysis entail” (James, 2007). The ethnographical descriptions are the author's description, and reality is simplified in order to communicate it. In discussing the politics of audience receptions, Caroline B Brettell (1993) suggests that the ethnographer's double role of closeness and distance to the participants' own understandings 
forms the ground for many controversies and strong negative reactions to what researchers have written. There are discrepancies between what research participants expect an ethnographer to do, and what ethnographers actually make out of interviews and observations. When studying up on professionals or specialists, one reason for the discrepancies may be that they are "treated as representatives rather than as experts" (Hammersley, 2014; 532). There may be a gap between a researcher's interpretation of a social phenomenon and how research participants think about their daily work (Hammersley, 2014: 533). The researcher analyzes the content of what the participants say and draws a theoretical conclusion in which utterances and constructions of arguments are used to illustrate a certain phenomenon.

The discrepancies between different expectations of research have an influence on the involvement of research participants. The question is whether researchers wish to involve those being studied or rather try to keep them at a critical distance in order not to get them involved (Gaztambide-Fernández \& Howard, 2012). The researcher is to some extent obliged to listen to, consider and negotiate participants’ views of how they are being represented, argue Gaztambide-Fernández and Howard (2012: 299). Ethnographers need to consider how they represent the institutions and the practitioners that have willingly opened their doors. Katrin Fangen (2005) poses two important questions in relation to representation: To what extent is the researcher critical and to what extent are the participants involved in the interpretation? She sees these as ethical questions and finds it equally ethically problematic to let participants determine the interpretation as to not let them influence the interpretation at all (Fangen, 2005).

Quite contrary to a humble attitude in relation to participants, Gaztambide-Fernandez (2015) presents a radical attitude of examining institutions built on inequality, such as elite schools. The general ethical goals of social science, and the ethical responsibility to society, may be in conflict with the ethical responsibility to participants (cf. Galliher, 1980). The privileged position of researchers is needed for examining and describing how privilege operates, argues Gaztambide-Fernandez (2015). In my studies of institutional interventions and sophisticated processes in which advanced technology are used to measure, weigh and alter children's bodies, I used my privilege as a researcher to examine and describe how normalization operates. I looked at how subsidized treatment, orthodontists' commissions, young people’s and their parents' wishes, advertising and competitive services interact and set the standards people wish to live up to. The goal was to point out knowledge production, clinical practices, 
economic and political conditions that influence the making and maintaining of different normalities.

In this article, I study 'sideways' in order to investigate the relation between research participants who are experts in the field and me as a researcher. The concept of 'sideways' is relevant because the experts and I shared an interest in the target group and their experiences. The ethnographic field study I draw upon was nevertheless a study in which I 'studied down', to use Nader's concepts (1972), in order to understand how children and young people act and reason when they participate in medical treatment, the goal being to understand the perspective of the targeted group. In analyzing my collaboration with the practitioners and their responses to my representations of the practice, I 'study up' (Nader, 1972) on a powerful institution whose acts of commission affect the lives of children and young people. Ethnographic research consists of multidirectional collaborations, in that studying patients, and practices as I do, includes 'studying up' on those who are set to care for the patients and on the politics governing the practice.

In focusing on how status dynamics shifted throughout the research process, I concentrated on activities and processes; the individual practitioners were not the main focus. The concept of power, in the Foucauldian sense (Foucault, 1979), does not refer to orthodontists who wield power individually or as a group. Rather, power is embedded in daily practices, in activities and routines at the clinic. Power also operates in the processes where biomedical technologies reach outside the clinic and are promoted by private business and public health systems (cf. Lock and Nguyen, 2010), such as marketing companies being charged with recruiting patients to the national dental health service, exposed to competition by private dental health businesses. 'Studying up' is thus a way of placing ethnographic work in a context of societal changes and understanding politics that has an impact on institutional networks and children's and young people's everyday lives. My efforts to collaborate and report back on the results demonstrate not only achievements and failures on my part but also give insights into burning questions and political conditions in the institution under study. Hopefully, it can shed light on how we can deal with our need to collaborate with practitioners and experts and what we can scientifically make of our efforts to do so. The aim for this article is to understand the politics of the practitioners' receptions of my research.

\section{The study - normalization processes in medicine}


In medical practice, normality and divergences are shaped when people are categorized on the basis of specific norms. In relation to children, this concerns practices where almost all children are measured and weighed (e.g. Hörnfeldt 2009), or where exposed children, for example, are treated for cleft lips and palates (e.g. Parens, 2006). In a project focused on controversial surgery, a colleague and I studied parents' experiences of having a child with ambiguous sex (Zeiler and Wickström, 2009). By looking at the interaction between doctors and parents, we provided a critical perspective of the practice of medical sex assignment (Zeiler and Wickström, 2009). Following up on the study, and interested in how medical technology changes definitions of normal and divergent (e.g. Olin Lauritzen \& Hydén 2007, Roberts 2010, Sandell 2010), I searched for a possible way to study orthodontics.

Orthodontics aroused my interest in that it targets a much greater part of the population compared to medical sex assignment and is hardly considered a normalization process. Nevertheless, it can serve as an example of medical practices in which young people's features are measured, judged and treated.

In Sweden, dental service is subsidized for children and young people between 0 and 22 years. General dentists and orthodontists are charged with making sure that every child gets a good occlusal development. If they identify a need for treatment with fixed or removable appliances, the costs for the treatment will be covered. Approximately 27 percent of children and young people receive such treatment. In 2012 I began a longer fieldwork at two orthodontic clinics. First of all, I studied three steps in a multistage process of examining and planning for orthodontic treatment that is common in countries where the cost is wholly or partially covered by public funds. The aim was to study how norms concerning teeth were done in practice in the interaction between young patients, parents, orthodontists and materiality, such as tools and visualizations of the bite. I attended and took field notes on 83 expert consultations (33 were audio-taped) where children and young people were examined quickly and got a recommendation for treatment or not. Together with the orthodontists, I invited the patients who were enrolled for treatment to take part in the study. Four girls and four boys (between 10 and 18 years old) together with their parents allowed me to follow the examinations and information on the treatment plans. I observed and video-recorded four examination sessions and eight information sessions and interviewed the patients, sometimes together with their parents. Apart from the recorded observations, I observed what was going on in the clinics and had informal conversations with orthodontists, assistants, technicians and odontologists during breaks and while waiting for patients. I also participated in 
specialist training for future orthodontists and in a national conference where orthodontists from all Swedish regions met.

From 2013 to 2014, I studied patients’ experiences of the actual treatment with braces. Six young patients were recruited and asked to trace the treatment process at their homes by producing video diaries during three specific weeks in the first year. I asked them to talk into the camera once a day and describe their experiences of having braces. After a week with a camera, the participants came for follow-up interviews. We looked at the beginning of every film and talked about the documentation. The participants produced 78 films and came for 19 follow-up interviews. The empirical results have previously been thoroughly reported elsewhere (Wickström, 2016; 2017) and will only be summarized here. In this article, I mostly use my field notes from other events and observations in which collaboration with the practitioners is in focus. I will structure my discussion around three central themes:

fluctuating positions and expectations, moments of interest: catching sight of another side of the body project, and moments of dissociation: downplaying the esthetic aspect.

\section{Fluctuating positions and expectations}

The start of the fieldwork in the two orthodontic clinics was smooth and easy. The director was enthusiastic about the collaboration and engaged orthodontists that were interested in participating in the study and recruiting patients to the project. The study was carefully prepared with information meetings for the staff and planning with the orthodontists. I communicated continuously with the director and the whole working team concerning my plans. In the introductory phase, the participating orthodontists gave advice on where in the process of evaluating the bite and planning for treatment it would be wise to conduct video observations, interviews and video diaries. They helped with inviting patients and their parents to the research project, administering information and collecting informed consent. In a recruiting letter to the invited patients, the orthodontists explained:

“The researcher's name is Anette Wickström and she is studying the conversations and interplay that take place between me, as a specialist dentist, our assistants and the patients who will receive braces. Anette is interested in how we at the clinic, together with the patient, discuss the row of teeth, what can be changed, and how that will influence the bite and appearance.”

The letter is interesting in several ways. First, because it demonstrates the practitioners' awareness of what I intended to study. Secondly, because it shows how my position 
fluctuated. I produced the invitation letters and informed consent but the orthodontists managed the invitation. I had no professional knowledge of the field of dentistry and had to be taught about everything from procedures to advanced technology. Finally, it shows the practitioners' different roles: the orthodontists were experts and possessed the professional knowledge, they were the inviter for the participants, and they agreed to step down from their position and be research subjects.

At the meeting, towards the end of three years of collaboration, it became obvious that the practitioners' expectations concerning my study differed considerably from what I had been doing. The clinical procedures at the orthodontic clinics are patient- and child-centered and the orthodontists devote a lot of time to explaining about the problems and the treatment plans for the patients and their parents. The orthodontists' mission is to identify those who are at risk and take action to support these individuals. Lately, they had identified increased pressure from the young patients and their parents and probably expected me to focus on how young people created norms for a nice smile. I focused, however, on the routines at the clinics, on how normal teeth and measures were defined and discussed in the interaction between orthodontists, patients and parents. Using a ruler and a slide caliper, the orthodontists measured and commented on problems and what could be improved in the patient's bite. Visualizations such as X-ray pictures, plaster casts of the jaws, pictures of the face and of the mouth from the outside and inside, ordered the planning for treatment. During information, the young patient and a parent sat in front of the computer, being guided through all the visualizations by the orthodontist who explained what needed to be done and the amount of work involved. In my analysis I demonstrated that the careful identification of divergences during examination and the suggestions for treatment during information introduced norms and set the standard for the esthetics of the bite (Wickström, 2016). In the article I argued that the visualizations of divergences and of the improved future bite became the foundation for aspirational norms, both at the clinic and in the patients' social lives. A practice intended to measure and safeguard children's and young people's health presented norms about appearances and how to take measures (Wickström, 2016). The orthodontists probably expected me to focus more on their perspectives and knowledge than on the institutional patterns and practices that established legitimacy.

When reflecting on the reactions to my article, I found that there was a gap between the orthodontists' view of their daily work and my analysis of how orthodontic practice routinely enacts norms and ideals by identifying divergences and present solutions. Martyn 
Hammersley (2014) argues that the gap is not as simple as the two parties having very different views of the world. The contrast between the different perspectives concerns a taken-for-granted world on the one hand, and paying attention to how the world is constituted on the other (Hammersley, 2014). If I had interviewed the orthodontists for the sake of getting information about their attitudes towards carrying out orthodontic work, the analysis would have represented the business close to how they see it. In contrast, observing the orthodontists' interaction with the patients, and their use of indexes, tools and visualizations, pays attention to discursive practices that build up social reality and people's identities (cf. Hammersley, 2014: 538). When a practitioner carries out the daily business, he or she does not see it as an attitude but as dealing with facts. The constructionist analysis forms a contrast in that it focuses on the discursive practices and how they function. In spite of the message in the recruiting letter sent to the patients, the orthodontists saw themselves as experts or research collaborators more than research subjects (cf. Hammersley, 2014). In the analysis of the practice they were treated as representatives rather than as experts.

The controversial aspect of my article was that it demonstrated that the activities at the clinic helped to create the norms and ideals that young people and their parents embrace (cf. Webster, 2002: 451). The insight that the norm is constructed in practice, however, has been touched upon among orthodontists. The following is a quote from an orthodontic handbook:

Divergences in the orthodontic sense are interpreted from a constructed norm for what a "normal” or "ideal” bite is. Divergences from the norm must never be regarded as illness. The diagnosis used in orthodontics must only be seen as morphological descriptions of deviations from the concept of a normal bite. Such deviations do not necessarily involve problems. [My own translation from Swedish.] (Mohlin et.al, 2008)

The handbook makes it clear that the norm and the deviance are constructed. Nevertheless, the role of the constructed norm in relation to what people desire is not discussed (cf. Lock \& Nguyen 2010; 302). My study of how norms are enacted in practice challenged a dominant ideology of scientific definitions of normality and the use of certain established criteria to diagnose abnormality (cf. Olin Lauritzen \& Hydén, 2007). The orthodontists were interested in the changed desires among the patients and their parents, but did not consider the issue as related to the orthodontic criteria for a normal bite.

\section{Moments of interest: Catching sight of another side of the body project}


One aspect of my research aroused interest during the meeting for the staff. It concerned the young patients' perspectives of the treatment. The interviews with the 14 patients that participated in the research revealed that almost all of them were enthusiastic about getting treatment with fixed appliances. Even those who were told that they would be fine without treatment took the chance to be treated if one minor aspect made them eligible. However, thanks to the combination of video diaries and follow-up interviews, two contradictory narratives of having braces were identified: suffering and success (Wickström, 2017). The video diaries demonstrated how the patients endured incalculable side effects and suffered from the regular tightening of the appliances. The interviews, on the other hand, presented the longing for change and the happiness over the initial successful signs thereof. Discussing this contradiction with the interviewees, I found that the two narratives mirrored the complex experience of going through treatment with fixed appliances. A boy who wished to have perfect teeth revealed his concerns about the treatment: "I feel a bit nervous about how much it will hurt and that I have to avoid things [soft drinks and sweets]”. His enthusiasm, however, outweighed the disadvantages. Being happy to transform the bite and the appearance, the young patients accepted making sacrifices. The work involved in the process seemed to them to be in reasonable proportion to the expected result. However, it was obvious that they could not foresee the extent of treatment or that they would probably need retainers for the rest of their life to minimize chances of relapse (Wickström, 2017).

The orthodontists did not see the patients at home struggling with their day-to-day handling of the side effects of treatment. Even if the orthodontists were contacted in cases with problems and heard complaints, the success narratives and the patients' gratitude were noticeable at the clinics. The list I presented of the sufferings the patients had reported in their films led an orthodontist to ask if it concerned only one of the patients. I explained that the list contained the most typical side effects reported in the video diaries during the first week with braces. The interested orthodontist clarified that he used to defuse such problems but now asked himself if he perhaps should change his routine. His question demonstrated that the treatment experiences in the everyday life of the patients were waved aside. At the orthodontic clinics, the improvements in the bite were emphasized while limitations on the body caused by appliances and the extent of the maintenance work were less in focus. However, there was a sort of balance of power. Orthodontists have to adapt to the patients' stamina. If the patients cannot keep their spirit up, take care of the delegated work at home, 
and make it all the way, the treatment has to be terminated. That makes the calculation of each patient's endurance part of the practice.

To sum up, the part of my analysis that aroused some interest concerned the narratives of suffering, the patients' statements about the negative sides of the treatment. This part did not touch upon the orthodontists' actions in the same scrutinizing way as when the focus was on their talk and gestures. The orthodontists' were not the direct subject of the analysis and probably this part of the result was closer to what they had expected. Being interested in conclusions that support or improve the activities rather than problematizing them, the findings that patients experienced more problems than the orthodontists thought, attracted the orthodontists' interest. This knowledge could eventually contribute to a change in the routines of information about the side effects of treatment.

\section{Moments of dissociation: Downplaying the esthetic aspect}

The heated question in relation to my research concerned the esthetic aspect of orthodontics. The picture of the billboard with the girl hiding her teeth that I had included in my article aroused the controversy. In practice, the esthetic aspect is constantly in focus, in visualizations of the problems and of the planned future bite, and in talk. The information sessions involve arguments about looking nicer and feeling happy (Wickström, 2016). In the article the orthodontists had read when I came to the meeting I demonstrate how visualizations, talk and gestures take part in creating norms and ideals about the bite. I refer to the report from the Swedish Council on Health Technology Assessment (SBU, 2005) which says that the most common reasons for orthodontic treatment are dentists', parents' or children's dissatisfaction with the esthetics of their bite. One of the orthodontists mentioned my reference to the report and emphasized that they often find problems in children's bite that are not visible. "Don’t you think we should say something?” she asked rhetorically. Another orthodontist claimed that esthetics is simply a side effect of orthodontic treatment. Both seemed to disagree with the arguments in my article. After the meeting, however, a young orthodontist explained to me that the older orthodontists do not want to acknowledge the esthetic aspects of orthodontics. The controversy could to a certain extent be attributed to differences of age, but it was more complex than that. Not only had patients and parents changed their attitude towards orthodontic treatment; technical progress in orthodontics had increased the possibilities to correct teeth and the argument for orthodontic treatment had to some extent shifted. 
Orthodontics, the branch of dentistry concerned with correcting teeth, was the first specialty in dentistry, and its point of departure was the esthetic value related to facial appearance. In 1952, Fischer stated in a textbook: "Since it [the 'ideal' normal standard] pictures 'ideal' relationships, it is seldom found in nature and is not always attainable in treatment” (Fischer, 1952: 57-58). Fischer does not see the chosen standard as an exact knowledge but as an ideal that is dependent on what is achievable. Over the years, there have been changes in the standards and in the technical advancements to achieve the ideal normal. Today the technical resources and procedures to change the bite and improve the smile are advanced. In a review of the sociology of oral health, the medical sociologist Catherine Exley (2009) describes a shift of emphasis in orthodontics from function to appearance. Internationally, debates within orthodontics have concerned the ethics of recruitment, uncertain benefit of orthodontic care and the risk of overuse of orthodontic treatment. Marc Ackerman (2010), Director of Orthodontics at Boston Children’s Hospital, demonstrates that the shift concerns the selling of services. In contemporary dentistry, instead of solely referring to the orthodontist's objective judgment, one parameter used is the self-perceived level of attractiveness related to the patient's own self-concept (Ackerman, 2010). Other orthodontists have argued that the social and psychological benefits from orthodontic treatment are uncertain (Shaw, 2012) and that the overuse of orthodontic services in public funded health care systems may lead to selfinduced over-treatment (Spassov et al., 2015; Braun \& Spassov, 2018). In Germany, the debate has caused the authority for financial control to critically examine the provision of orthodontic services in the public health care system (German Federal Court for Auditors, 2018). The debate demonstrates an awareness of the problematic aspects of the emphasis on esthetic aspects.

There are also changes in the reasons used to justify treatment. Debra Gimlin (2007) argues that when healthcare is publicly funded, cosmetic surgery is legitimated with reference to medical need and the risk of social exclusion. The fact that orthodontics in Sweden is state financed may feed arguments for medical need even when the reasons are mainly cosmetic. A common argument I heard from patients and orthodontists was that treatment would prevent future headaches, although research demonstrates that it is difficult to foresee any consequences of a malocclusion (Ackerman et al., 2007). Parallel to the shift in how orthodontics is marketed and justified, patients' and parents' requests have increased (e.g. Boström, 2010). At the orthodontic clinics, norms concerning teeth standards and references to psychosocial health intersect, and the technical requirements are available to provide 
improvement and satisfy patients' requests. My research demonstrated that these changes are interrelated, and that orthodontic practices interact with societal norms and people's identity work (Wickström, 2016).

My article pinpointed a changing social and medical landscape in which esthetics is recognized as being important to wellbeing and as an indicator of a healthy state (cf. Edmonds, 2013). Health and esthetics become entangled in medical practices and the orthodontists are in the middle of these changes. The article was also a delicate subject in that it came at a time when the justification of orthodontics was being considered. At a conference where orthodontists discussed the challenges they are facing, they touched upon the question. The orthodontists found themselves faced with increasing demands from patients and parents. At the same time they considered the state subsidies insufficient because they might have to raise the limit for treatment. (In the Swedish county where I did my fieldwork, the lower limit for treatment was set at the upper half of mild divergences in ICON, the Index of Complexity, Outcome and Need (Daniels \& Richmond, 2000).) The two representations of the state of orthodontic practice, patients requesting too much and state subsidies being too low, indicate that the position of orthodontics is to some extent contradictory. Orthodontists have to keep treatment on a reasonable level but also argue for its existence. Orthodontics is a small part of state-financed healthcare and relies on political decisions. Having to monitor and advocate the continuation of state benefits may obstruct acknowledging orthodontics' own role in creating norms and ideals.

The sensitive topic of state benefits may divide different specialties in dentistry. Participating in a program for dentists specializing in orthodontics, I found that some dentists worried about their choice of specialization, given the risk that the dental benefits for orthodontics might be withdrawn and that their employment opportunities would decrease or change drastically. This general worry constitutes the broader context of meaning for the tendency to downplay the esthetic aspects of orthodontics. Different positions in dentistry however, may also cause practitioners to notice and reflect differently on dentistry's involvement in contributing to social norms concerning teeth. An entrepreneur who runs an internet site for teeth whitening responded to a popular article about my research findings on Linköping University’s website: 
My God - a good and readable article, really! I run an Internet site for teeth whitening and I certainly started reflecting on what this means and what I contribute. This gave me something to think about!

It might be easier for an entrepreneur who declares that his business concerns cosmetic to question the effects of his practice, in comparison to orthodontists who are commissioned by the state to ensure that children and young people have good oral health and at the same time need to advocate the continuation of state benefits.

Health - as manifested in the realm of the esthetic - holds a strong position in society. And medicine, argues Annmarie Mol (2002: 60), sets the standards modern people wish to live up to. Every orthodontist has to consider and deal with changing conditions and demands. In order to defend their practice, orthodontists see the need to distance their own practice from cosmetic surgery and emphasize medical needs and psychosocial benefits. Doing research in the field, I ended up in the middle of the changes with an analysis that was questioned by practitioners who sought to defend their position. What was actually at stake during the meeting was the changing conditions in orthodontics related to the entanglement of health and appearances (Ackerman, 2010). The orthodontists tried to downplay the role of esthetics as well as the role of orthodontic practice in increasing demands from young patients and their parents.

\section{Discussion}

Ethnographic research into major institutions and organizations is intended to pose other questions than those raised by the practitioners who work in the organizations. The ethnographic representations of the practices may be contradictory to the practitioners' picture of their work, as they are probably more interested in improving than in problematizing their activities. The research questions may be directed at social and political processes as well as at differences between actors in the field. My analysis of orthodontic practice was meant to open the window on new aspects of the institutional work and give perspectives on how the activities contribute to the changes in patients' requests that the orthodontists had recognized, perspectives that will create knowledge about systems that influence people's lives in general (cf. Nader, 1972). In order to represent what is going on in the field, the researcher has to balance between closeness, to being engaged in the participants' perspectives and interpretations, and distance, which means taking a careful and critical look at the processes (e.g. Fangen, 2005). This can be problem free, but what happens 
if practitioners have strong opinions on how their practice is represented? According to Gaztambide-Fernandez and Howard (2012; 297) the question of how research subjects try to control how they are portrayed is not adequately discussed in the literature. A common strategy among researchers is to distance themselves from their research subjects. As an alternative, Gaztambide-Fernandez (2015) argues that researchers can use their position to examine how privilege operates.

When I invited the participants to comment on my representations of the practice, I was interested in their reactions and views on a slightly different basis. How did they consider the workings of their practice, the effects on norms and the strategies used by the young patients? Being subjected to the orthodontists' feelings of betrayal caused me to draw back and question my ability to contribute to the practice, as well as to clear the way for other social scientists studying medical practices. When directing my focus on the practitioners' reactions instead, the position that the orthodontists took became irreplaceable information about what was going on politically and socially in the field.

Analysis of how status dynamics shift during the research project and of reactions to ethnographic representations can, first of all contribute to knowledge about the power balance that arises in collaboration projects. Secondly, elaborations of how the study results are received by the experts sheds light on social changes and politics that affect people's everyday lives. The examples of collaboration and of friction I have presented demonstrate that studying sideways the power dynamics involved in collaboration sheds light on political processes that influence children's and young people's activities and social lives (cf. Nader, 1972). The reactions to my analysis revealed that the study had pointed out problematic circumstances in the field.

Dentistry has experienced far-reaching changes concerning the discourse of health and orthodontic needs. Orthodontics is part of the changing medical landscape in which health manifests itself in esthetic qualities (cf. Edmonds, 2013). The orthodontists in the research project knew from the beginning what was going on in their field of knowledge, that is, the entanglement of health and esthetics. I, the researcher, did not realize at first what I was getting into. It was not until I began analyzing the processes and involving the practitioners in the interpretation that the shifting medical landscape became obvious. The discussions with the orthodontists revealed that they did not acknowledge the role of clinical practice in 
increasing demand, partly because of their need for political advocacy of orthodontic practice and to keep themselves apart from cosmetic surgery.

My position as an academic and the power that lies in writing enabled me to share my experiences and analysis. I used my privilege as a researcher (cf. Gaztambide-Fernandez, 2015) to make visible scientific, economic and political factors that are part of the normalization of children's bodies. But even if the project sprang from a shared interest in the question of normalization processes, the analysis of how norms are enacted in practice was not what the orthodontist had expected. The responses to my representation of orthodontic practice help to illustrate the usefulness of scrutinizing collaboration, as I have been arguing here. How collaboration with practitioners evolves during fieldwork and how the researcher's representations of powerful institutions are received or questioned constitutes useful information about institutional networks. In relation to emergent research policies on collaboration with surrounding society (Wise et al., 2016), I would in fact argue that we need to give as much value to friction as to agreements if we try to incentivize researchers' ability to collaborate. Scrutinizing friction in collaboration projects can tell us about the political conditions that govern the activities. Using cooperative efforts to understand the burning political and social questions can illustrate the ways in which institutional networks are part of setting the conditions for people's lives.

\section{Funding}

This article reports on research funded by the Swedish Research Council (Reg. No. 4352011-1220 and 421-2012-992).

\section{References}

Ackerman, James L., Marc B. Ackerman and Martin R. Kean (2007) A Philadelphia Fable: How Ideal Occlusion Became the Philosopher's Stone of Orthodontics. Angle Orthodontist 77(1):192-194.

Ackerman MB (2010) Selling orthodontic need: Innocent business decision or guilty pleasure? Journal of Medical Ethics 36: 275-278.

Boström C (2010) Tandställningen har blivit trendig [Braces have become trendy]. Östgöta Correspondenten August 25. 
Boyer D and Hannerz U (2006) Introduction: Worlds of journalism. Ethnography 7(1): 517.

Braun B and Spassov A (2018) Kieferorthopädische Behandlung von Kindern und Jugendlichen im Spiegel von Routinedaten (2012-2017). hkk Krankenkasse Gesundheitsreport.

Brettell CB (ed.) (1993) When they read what we write. The politics of ethnography. Westport, Conn.: Bergin \& Garvey.

Daniels C and Richmond S (2000) The Development of the Index of Comoplexity, Outcome and Need (ICON). Journal of Orthodontics 27: 149-162.

Edmonds A (2013) Can medicine be aesthetic? Disentangling beauty and health in elective surgeries. Medical Anthropology Quarterly 27(2): 233-252.

Erickson F (2006) Studying side by side: Collaborative action ethnography in educational research. In: Spindler G and Hammond L (eds) Innovations in educational ethnography. Theory, methods, and results.

Exley C (2009) Bridging a gap: The (lack of a) sociology of oral health and healthcare. Sociology of Health and Illness 31(7): 1093-1108.

Fangen K (2005) Deltagande observation. Malmö: Liber AB.

Fischer B (1952) Orthodontics: Diagnosis, prognosis, treatment. Philadelphia: WB Saunders Company.

Foucault M (1979) Discipline and punish: The birth of the prison. Penguin: Harmondsworth. Galliher J (1980) Social scientists’ ethical responsibilities to superordinates: Looking upward meekly. Social Problems 27(3): 298-308.

Gaztambide-Fernandez RA (2015) Elite entanglements and the demand for a radically un/ethical position: the case of Wienie Night. International Journal of Qualitative Studies in Education.

Gaztambide-Fernandez RA and Howard A (2012) Access, status, and representation: Some reflections from two ethnographic studies of elite schools. Anthropology and Education 43(3): 289-305. 
German Federal Court for Auditors (2018) Nutzen kieferorthopädischer Behandlung muss endlich erforscht warden. Bundesministerium fur Gesundheit, Einzelplan 15. Kapitel 1502. Titel 63606.

Gimlin D (2007) Accounting for cosmetic surgery in the USA and Great Britain: A crosscultural analysis of women's narratives. Body and Society 13(1): 41-60.

Gusterson H (1997) Studying up revisited. Political and Legal Anthropology Review 20(1): 114-119.

Hammersley M (2014) On the ethics of interviewing for discourse analysis. Qualitative Research 14(5): 529-541.

Hammond L and Spindler G (2001) Not talking past each other: Cultural roles in education research. Anthropology \& Education Quarterly 32(3): 373-378.

Hörnfeldt H (2009) Prima barn, helt u.a. Normalisering och utvecklingstänkande i svensk barnhälsovård 1923-2007. [Normalisation and developmental thinking in Swedish health care 1923-2007]. Makadam förlag.

James A (2007) Giving voice to children's voices: Practices and problems, pitfalls and potentials. American Anthropologist 109(2): 261-272.

Lock M and Vinh-Kim N (2010) An Anthropology of Biomedicine. Chichester: WileyBlackwell.

Mohlin B, Follin M and Hagberg C (2008) Ortodonti. Varför? När? Hur? [Orthodontics. Why? When? How?]. Stockholm: Gothia.

Mol A (2002) The body multiple: Ontology in medical practice. Durham: Duke University Press.

Nader L (1972) Up the anthropologist: Perspectives gained from studying up. In: Hymes D (ed) Re-inventing anthropology. New York: Vintage.

Olin Lauritzen S and Hydén LC (eds.) (2007) Medical technologies and the life world. The social construction of normality. London: Routledge.

Parens E (ed.) (2006) Surgically Shaping Children; Technology, Ethics, and the Pursuit of Normality. Baltimore: The John Hopkins University Press. 
Roberts C (2010) Defining the pubescent body: Three cases of biomedicine’s approach to 'pathology'. In Johnson, E. \& Berner, B. (eds.) Technology and Medical Practice. Blood, Guts and Machines. London: Ashgate.

Rosaldo R (1987) When natives talk back: Chicano anthropology since the late sixties. Tucson: University of Arizona, Renato Rosaldo lecture series monograph Vol. 2. Cited in Brettell CB (ed.) (1993) When they read what we write. The politics of ethnography. Westport, Conn.: Bergin \& Garvey. Pp. 20-21.

Sandell K (2010) Learning to produce, see and say the (ab)normal: Professional vision in ultrasound scanning during pregnancy. I Johnson, E. \& Berner, B. (red.) Technology and Medical Practice. Blood, Guts and Machines. London: Ashgate.

SBU, Swedish council on health technology assessment (2005) Bettavvikelser och tandreglering i ett hälsoperspektiv. Report 176. [Bite abnormalities and orthodontic treatment from a health perspective].

Shaw B (2012) Uncertainty of Orthodontic Benefit and the Questionable Ethics of Marketing. Seminars in Orthodontics 18(3): 210-216.

Spassov A, Betting H and Pavlovic D (2015) From misinformation to overtreatment. Letters to the editor. American Journal of Orthodontics and Dentofacial Orthopedics 147: 295.

Staller KM (2012) Epistemological boot camp: The politics of science and what every qualitative researcher needs to know to survive in the academy. Qualitative Social Work 12(4): 395-413.

Webster A (2002) Innovative health technologies and the social: Redefining health, medicine and the body. Current Sociology 50: 443-457.

Wickström, Anette (2017) “One step at a time”: Analyzing young patients’ video diaries in an ethnographic tracing of fixed appliances. Children \& Society 31(3): 183-193.

DOI:10.1111/chso.12179

Wickström, Anette (2016) “I hope I get movie-star teeth” - doing the exceptional normal in orthodontic practice for young people. Medical Anthropology Quarterly 30(3):285-302. DOI: 10.1111/maq.12247 
Wise E, Berg M, Landgren M, Schwaag S S, Benner M and Perez V E (2016) Evaluating the role of HEIs' interaction with surrounding society. Developmental pilot in Sweden 20132016. Vinnova Report 2016:09.

Zeiler, Kristin \& Wickström, Anette (2009) Why do “we” perform surgery on newborn intersexual children? The phenomenology of the parental experience of getting a child with unclear sex. Feminist Theory 10(3):359-377. 